\title{
Concerns About Exercise Are Related to Walk Test Results in Pulmonary Rehabilitation for Patients with COPD
}

\author{
Maarten J. Fischer • Margreet Scharloo • Jannie Abbink • \\ Alex van 't Hul • Dirk van Ranst - Arjan Rudolphus • \\ John Weinman • Klaus F. Rabe • Adrian A. Kaptein
}

Published online: 16 November 2010

(C) The Author(s). This article is published with open access at Springerlink.com 2010

\begin{abstract}
Background Although international guidelines on pulmonary rehabilitation acknowledge that psychological factors contribute to exercise intolerance in patients with chronic obstructive pulmonary disease (COPD), the few empirical studies investigating this association have found inconsistent results.

Purpose The purpose of this study is to investigate whether negative affect and beliefs about exercise of patients with COPD would be related to baseline 6-min walk (6-MW) test results in a pulmonary rehabilitation setting, after correction for physical variables (sex, age, height, weight, and lung function). A second aim was to examine whether
\end{abstract}

M. J. Fischer $(\bowtie) \cdot$ M. Scharloo • A. A. Kaptein

Medical Psychology, Leiden University Medical Center (LUMC),

P.O. Box 9555, 2300 RB Leiden, the Netherlands

e-mail: m.j.fischer@lumc.nl

J. Abbink

Rijnlands Rehabilitation Center,

Leiden, the Netherlands

A. van 't Hul · D. van Ranst

Pulmonary Rehabilitation Unit, Rehabilitation Center Breda,

Breda, the Netherlands

\author{
A. Rudolphus \\ Department of Pulmonary Diseases, Sint Franciscus Gasthuis, \\ Rotterdam, the Netherlands
}

J. Weinman

Health Psychology Section, Institute of Psychiatry,

Thomas Guy House,

London, UK

K. F. Rabe

Department of Pulmonology,

Leiden University Medical Center (LUMC),

Leiden, the Netherlands patients' beliefs are associated with treatment outcomes, as measured by an improvement in 6-MW distance.

Method A 12-week pulmonary rehabilitation program was completed by 166 patients. Beliefs (perceived necessity and concerns) about exercise and negative affect were assessed by a questionnaire. Clinical data were obtained from medical records.

Results Baseline 6-MW distance was positively related to younger age, male gender, better pulmonary function, and having fewer concerns about exercise. After rehabilitation, patients had increased their walk distance by $12 \%$ (32 m), on average. Baseline physiological and psychological variables were unrelated to patients' response to treatment (increase in walk distance). However, subgroup analysis showed that for patients with mild to moderate airflow obstruction, concerns about exercise were negatively related to response to treatment.

Conclusion We conclude that patients' beliefs about the negative consequences of exercise are associated with baseline 6-MW test performance and response to treatment for patients with mild to moderate COPD. We recommend that patients' concerns about exercise are discussed and, if necessary, corrected during the intake phase.

Keywords Chronic obstructive pulmonary disease . Exercise training · Negative affect · Pulmonary rehabilitation $\cdot$ Self-regulation $\cdot$ Treatment beliefs

\section{Introduction}

International guidelines on pulmonary rehabilitation state that, apart from pathophysiological mechanisms, psychological processes are likely to influence exercise intolerance in patients with chronic respiratory conditions [1]. However, 
the few empirical studies that have investigated this assumption to date have been inconsistent in their conclusions. Borak et al. have concluded that "exercise tolerance in COPD is not affected by abnormalities in emotional status" [2]. In a later study, Trappenburg et al. concluded that the outcome of pulmonary rehabilitation is independent of patients' baseline psychological and sociodemographic characteristics [3]. By contrast, more recent studies by Cully [4] and Giardino [5] found a significant negative association between general anxiety and exercise test results, calling for further investigation into the role of negative affect in exercise tolerance.

In addition to the impact of patients' affect on behavior, leading behavioral theories emphasize the role of individual's beliefs regarding a particular object, event, or action that shape a person's motivation to perform a certain behavior [6, 7]. Within the context of health behavior, the Necessity-Concerns framework [8] was developed to explain how patients' beliefs about treatment influence treatment adherence. As an extension to Leventhal's Common Sense Model of self-regulation [9, 10], the central assumption of this framework is that the motivation to comply with a certain treatment regimen depends on the perceived necessity (potential benefits) of this particular treatment and specific concerns (costs or risks) patients may have about the proposed treatment. Additionally, by influencing adherence to medical protocols, patients' beliefs about treatment are likely to be related to health outcomes [11]. Previous studies have found evidence for the assumed influence of patients' treatment beliefs on patients' compliance with treatment regimens [12-18] and treatment outcomes in physical therapy programs [19-21].

As physical exercise is an important predictor of physical condition in patients with chronic obstructive pulmonary disease (COPD) and serves as the cornerstone of pulmonary rehabilitation programs $[1,22,23]$, investigating how patients' beliefs about exercise are related to baseline exercise tolerance and treatment outcomes after rehabilitation is relevant for the interpretation of exercise test results and holds potential value for patient education.

The aim of this study is to test the hypothesis that patients' beliefs about exercise are related to baseline walk test results, after correcting for the influence of physical variables and general negative affect. Following assumptions of the Necessity-Concerns framework, patients' motivation to engage and persist in strenuous exercise during a pulmonary rehabilitation program is likely to be higher with increased perceived necessity of engaging in this exercise program, whereas it is expected to be lower when patients have serious concerns about the negative effects of treatment. Since models of health behavior have greater explanatory power as their contents become more specific to the behavior in question $[24,25]$, it is expected that specific beliefs about the exercise program are more closely related to exercise performance than general negative affect.

A second aim is to investigate whether patients' treatment beliefs are related to response to treatment (increase in walk distance). We expect the relationship of treatment beliefs and treatment outcomes in particular for those patients with mild to moderate airway obstruction, who are less likely to be limited by physiological complications and comorbidity associated with advancing disease, and hence may have a greater potential to train at higher intensity [26]. The 6-min walk (6-MW) test was chosen as outcome variable, as it is one of the most widely used field tests for the assessment of patients' exercise tolerance and an important indicator of response to treatment $[1,27,28]$. Age, gender, weight, and height have been found to be the most important independent predictors of the 6-MW distance in healthy subjects [29, 30]. These four variables will serve as control variables in the analyses together with the degree of airway obstruction (percentage of predicted forced expiratory volume in $1 \mathrm{~s}$ ( $\mathrm{FEV}_{1} \%$ pred)), which has been found to be a significant predictor of walk test results in a healthy elderly population and in patients with COPD [2, 27, 31-33] and is considered as the principle indicator of disease severity in COPD [34].

\section{Methods}

\section{Procedure}

This study was part of a larger study on dropout and nonattendance in pulmonary rehabilitation programs. Patients who had been referred to one of three centers for pulmonary rehabilitation (Rijnland Rehabilitation Center (RRC), Rehabilitation Center Breda (RCB), and Sint Franciscus Gasthuis (SFG)) were invited to participate in this study during the intake phase. All patients provided written informed consent and gave the researchers permission to obtain sociodemographic and clinical data from their medical files. Patients who participated received a questionnaire and were requested to return it before the start of the rehabilitation program. Patients who had already started rehabilitation or had primary lung conditions other than COPD were excluded from the study. The study was approved by the SFG and Leiden University Medical Center (LUMC) ethics committees and the boards of the three rehabilitation centers.

\section{Rehabilitation Program}

Rehabilitation programs were organized following ATS/ERS guidelines for pulmonary rehabilitation [1]. The program was 12 weeks in duration and consisted of supervised exercises 
(strength and endurance training of the lower and upper limbs, recreational sports, and activities of daily living), relaxation training, and breathing exercises. Group education focused on several aspects of disease management such as inhalation technique, nutrition, and coping with the social and psychological consequences of living with COPD. As comprehensive rehabilitation programs are tailored to the needs of the individual patient, optional treatment modalities consisted of counseling by a psychologist or social worker, nutritional interventions, occupational therapy, and smoking cessation counseling. All rehabilitation centers offered an outpatient program of 3 days a week. In RCB, an intensive program of 5 days a week was also available.

\section{Baseline Assessment}

Before entering the rehabilitation program, participants filled out a questionnaire which included sociodemographic questions, negative affect, and patients' perceived necessity and concerns regarding exercise. Negative affect was assessed by means of the hospital anxiety and depression scale (HADS) [35], a reliable and valid instrument measuring anxiety and depression (seven items for each subscale) on a four-point scale. Perceived necessity and concerns were assessed on two Likert-type seven-point scales (see Appendix). The items were originally designed and validated for use in cardiac rehabilitation research [13] and slightly modified to be suitable for use in an elderly COPD population (e.g., "resume my activities" instead of "return to work"). Scores for the necessity and concerns subscales are represented as the mean of the individual items. Both scales showed acceptable internal consistency in the present study (Cronbach's $\alpha=0.68$ (necessity) and $\alpha=0.65$ (concerns)).

Baseline pulmonary function tests included postbronchodilator forced expiratory flow rates and vital capacity according to recommended standards [36]. A classification of disease severity (GOLD stage I-IV) was made according to international guidelines [37]. Higher GOLD stages represent worse lung function. Patients' body mass index and fat free mass index were assessed during the intake and provide an indication of the systemic effects of the disease.

The 6-MW test was used to assess patients' functional exercise performance. During the 6-MW test, subjects are asked, with standardized encouragement, to cover as much distance as possible. Distance walked and Borg scores, measuring patients' fatigue and dyspnea [38], were recorded after the walk test. A percentage of predicted walk distance was calculated by dividing patients' distance walked by predicted walk distance (with correction for sex, age, height, and weight). The formulas of Troosters et al. were used to calculate patients' predicted walk distances
[30]. The 6-MW test was performed before the start of the formal program and again at the end of the rehabilitation program.

\section{Statistical Analyses}

Descriptive statistics (frequency, mean, and standard deviation) was used to present patients' sociodemographic and medical characteristics. T-tests and correlation analyses were performed to investigate the associations between sociodemographic and medical characteristics and patients' treatment beliefs. Linear hierarchical regression analysis with forced entry was performed to establish the relationship between clinical variables, negative affect, and patients' treatment beliefs with baseline 6-MW distance (in meters). Gender, age, weight, and height were entered in the first model. Airway obstruction (forced expiratory volume in first second of expiration, expressed as percentage of predicted value ( $\mathrm{FEV}_{1} \%$ pred)) was added in the second model. Anxiety and depression (HADS) symptoms were added in the third model. The final model included gender, age, weight, height, $\mathrm{FEV}_{1} \%$ pred, negative affect, and patients' necessity beliefs and concerns regarding the exercise program.

With regard to treatment response, differences in walk distance are expressed as percentage of the pretreatment value [39]. Investigation of this variable showed that it had a non-normal distribution (Kolmogorov-Smirnov $Z=1.85$, $p=.002)$. In order to facilitate the interpretation of results, it was decided to dichotomize this variable for further analyses. An increase in distance walked of $10 \%$ or more relative to baseline is generally accepted as a minimal important difference (MID) [40] and is considered as an indication of treatment response. Therefore, this degree of improvement was chosen as a cutoff point to create two subgroups: those who achieved the MID of $10 \%$ or more increase in $6-\mathrm{MW}$ and those who did not achieve this MID. Multivariate analysis of variance (MANOVA) was performed to explore whether patients who improved their walk distance with $10 \%$ or more differed from those who had not achieved the MID in sociodemographic and clinical variables, negative affect, or treatment beliefs.

To test our hypothesis that the association of patients' treatment beliefs and treatment response depends on patients' degree of airway obstruction, we conducted a moderation analysis following steps outlined by Frazier et al. [41]. In a hierarchical logistic regression model, the main effects of $\mathrm{FEV}_{1} \%$ pred and treatment beliefs on treatment outcome (percentage increase in walk distance) were entered in the first step. In the second step, the interaction terms (the product of centered variables) of airway obstruction and treatment beliefs were entered. 


\section{Results}

Two hundred and seventeen patients entered the rehabilitation program, of which 166 (77\%) completed the program. Data on dropout are reported elsewhere [42]. No differences were found in patients' treatment beliefs between dropouts and patients who completed the rehabilitation. Differences in medical or sociodemographic variables at baseline between dropouts and completers were also not significant [42].

Baseline characteristics of those patients who completed the rehabilitation program are presented in Table 1. Sixtythree percent of the patients were classified as having severe or very severe COPD ( $\mathrm{FEV}_{1} \leq 50 \%$ of predicted value). No differences in baseline 6-MW distances were observed between patients who entered a compact program and patients who entered an intensive program (390 vs. $369 \mathrm{~m}$, respectively; $t=1.22, p=.22$ ). The percentage of predicted walk distance was also approximately similar (76\% vs. $72 \%$, respectively; $t=0.93, p=.35$ ).

Women and men held comparable views regarding treatment necessity $(t=-0.58, p=.57)$ and concerns about treatment $(t=-0.42, p=.68)$. Correlation analyses revealed that associations between patients' treatment beliefs and age, height, weight, and pulmonary function were also nonsignificant (see Table 2). Perceived necessity and concerns showed a negligible negative relationship $(r=-0.08, p=.32)$.

Association of Treatment Beliefs and Baseline Walk Test Performance

Results from the hierarchical regression analysis showed that in the first model (with gender, age, weight, and height as predictors), age showed a highly significant relationship with walk distance (Table 3 ). In the second model, $\mathrm{FEV}_{1} \%$ pred was the most important predictor of walk distance. Age remained a significant predictor of walk distance. After correction for differences in lung function, males performed somewhat better than females on the 6-MW test (difference approximately $40 \mathrm{~m}$ ), although this did not reach statistical significance $(t=-1.74, p=.08)$. In the third model, anxiety and depression were added. These variables were unrelated to baseline 6-MW distance. In the final model, patients' exercise beliefs were added. This analysis showed that patients' concerns about exercising were negatively related to baseline walk test results after controlling for patients'
Table 1 Patient characteristics at baseline $(N=166)$

$F E V_{1}$ forced expiratory volume in $1 \mathrm{~s}, \mathrm{VC}$ vital capacity, $\mathrm{SaO} 2$ arterial blood oxygen saturation at rest, $6 M W D$ 6-min walk distance, $6 M W D$ (\%pred) percentage of predicted 6-min walk distance, $H A D S$ hospital anxiety and depression scale

\begin{tabular}{lll}
\hline & Mean & SD \\
\hline Sex $(N, \%)$ & & \\
Female & 75 & $45 \%$ \\
Male & 91 & $55 \%$ \\
Age & 63.0 & 9.4 \\
Height $(\mathrm{cm})$ & 169 & 10.0 \\
Weight $(\mathrm{kg})$ & 77.5 & 17.6 \\
Body mass index $\left(\mathrm{kg} / \mathrm{m}^{2}\right)$ & 27.0 & 5.8 \\
Fat free mass index $\left(\mathrm{kg} / \mathrm{m}^{2}\right)$ & 16.9 & 2.8 \\
FEV $(1)$ & 1.27 & 0.6 \\
FEV $(\%$ pred) & $46 \%$ & 19.2 \\
GOLD stage $(N, \%)$ & & \\
I & 13 & $8 \%$ \\
II & 49 & $30 \%$ \\
III & 66 & $40 \%$ \\
IV & 38 & $23 \%$ \\
VC (l) & 3.38 & 1.0 \\
VC (\%pred) & $95.5 \%$ & 20.0 \\
SaO2 rest, \% & $94.6 \%$ & 2.5 \\
6MWD (m) & 381 & 111.0 \\
6MWD (\%pred) & $74 \%$ & 21.9 \\
Borg fatigue, post-6MWD & 4.4 & 2.3 \\
Borg dyspnea, post-6MWD & 4.8 & 2.1 \\
HADS anxiety & 7.3 & 4.8 \\
HADS depression & 7.6 & 1.1 \\
Treatment necessity & 5.4 & 1.4 \\
Treatment concerns & 2.9 & \\
\hline & & \\
& & \\
& &
\end{tabular}


Table 2 Association of treatment beliefs with sociodemographic and clinical variables and negative affect

\begin{tabular}{|c|c|c|c|c|}
\hline & Necessity & $p$ & Concerns & $p$ \\
\hline \multicolumn{5}{|l|}{ Sex (mean score) } \\
\hline Males & 5.4 & & 2.9 & \\
\hline Females & 5.5 & $.57^{\mathrm{a}}$ & 3.0 & $.68^{\mathrm{a}}$ \\
\hline Age & -0.09 & .25 & -0.05 & .57 \\
\hline Weight & 0.04 & .59 & -0.12 & .11 \\
\hline Height & -0.12 & .12 & -0.11 & .17 \\
\hline $\mathrm{FEV}_{1} \%$ pred & -0.04 & .58 & 0.02 & .83 \\
\hline HADS anxiety & 0.08 & .30 & 0.22 & .004 \\
\hline HADS depression & -0.06 & .45 & 0.24 & .002 \\
\hline
\end{tabular}

Values are presented as Pearson $r$ scores unless stated otherwise

$F E V_{1}$ forced expiratory volume in $1 \mathrm{~s}, H A D S$ hospital anxiety and depression scale

${ }^{\mathrm{a}} t$ test clinical variables and negative affect. Perceived necessity of treatment was not related to baseline walk test results.

Improvement in 6-MW Distance

Of the 166 patients who completed the rehabilitation program, 139 patients (84\%) underwent a post-treatment 6-MW test. Exacerbations in the final weeks before the end of the rehabilitation program and patients not showing up were responsible for incomplete follow-up data. No differences in baseline distance walked were observed between patients who underwent a post-treatment 6-MW test and those who did not (380 and $392 \mathrm{~m}$, respectively $(t=0.44, p=.66)$.

On average, patients had increased their walk distance with $12 \%$ (median $=+10 \%$, range $=-45 \%$, $+217 \%)$. Absolute walk distance had increased with $32 \mathrm{~m}$, on average ( median $=+35 \mathrm{~m}$; range $=-197$ to $+258 \mathrm{~m})$. No differences

Table 3 Predictors of baseline 6-min walk distance $(N=153)$

\begin{tabular}{|c|c|c|c|c|c|c|c|}
\hline & \multirow[t]{2}{*}{ Predictors } & \multirow[t]{2}{*}{$B$} & \multirow[t]{2}{*}{ Beta } & \multirow[t]{2}{*}{$p$} & \multicolumn{2}{|c|}{ Model fit } & \multirow[t]{2}{*}{$p$} \\
\hline & & & & & $R^{2}$ & $F$ & \\
\hline \multirow[t]{4}{*}{ Model 1} & $\operatorname{Sex}^{\#}$ & -29.00 & -0.13 & .24 & \multirow[t]{4}{*}{0.057} & \multirow[t]{4}{*}{2.23} & \multirow[t]{4}{*}{.07} \\
\hline & Age & -2.83 & -0.24 & .01 & & & \\
\hline & Weight & -0.06 & -0.01 & .92 & & & \\
\hline & Height & 22.59 & 0.02 & .87 & & & \\
\hline \multirow[t]{5}{*}{ Model 2} & Sex & -40.47 & -0.18 & .08 & \multirow[t]{5}{*}{0.175} & \multirow[t]{5}{*}{6.22} & \multirow[t]{5}{*}{$<.001$} \\
\hline & Age & -2.71 & -0.23 & .01 & & & \\
\hline & Weight & -0.77 & -0.12 & .16 & & & \\
\hline & Height & 78.33 & 0.07 & .54 & & & \\
\hline & $\mathrm{FEV}_{1} \%$ pred & 2.11 & 0.36 & $<.001$ & & & \\
\hline \multirow[t]{7}{*}{ Model 3} & Sex & -40.35 & -0.18 & .09 & \multirow[t]{7}{*}{0.175} & \multirow[t]{7}{*}{4.38} & \multirow[t]{7}{*}{$<.001$} \\
\hline & Age & -0.70 & -0.23 & .01 & & & \\
\hline & Weight & -0.77 & -0.12 & .16 & & & \\
\hline & Height & 78.74 & 0.07 & .54 & & & \\
\hline & $\mathrm{FEV}_{1} \%$ pred & 2.12 & 0.36 & $<.001$ & & & \\
\hline & HADS anxiety & -0.02 & -0.00 & .99 & & & \\
\hline & HADS depression & 0.10 & 0.00 & .97 & & & \\
\hline \multirow[t]{9}{*}{ Model 4} & Sex & -42.38 & -0.19 & .08 & \multirow[t]{9}{*}{0.204} & \multirow[t]{9}{*}{4.08} & \multirow[t]{9}{*}{$<.001$} \\
\hline & Age & -2.66 & -0.22 & .01 & & & \\
\hline & Weight & -0.95 & -0.15 & .09 & & & \\
\hline & Height & 75.56 & 0.06 & .56 & & & \\
\hline & $\mathrm{FEV}_{1} \%$ pred & 2.23 & 0.38 & $<.001$ & & & \\
\hline & HADS anxiety & 0.10 & 0.00 & .97 & & & \\
\hline & HADS depression & 1.36 & 0.05 & .66 & & & \\
\hline & Necessity & 4.77 & 0.05 & .54 & & & \\
\hline & Concerns & -13.46 & -0.17 & .03 & & & \\
\hline
\end{tabular}

\# Sex was coded $1=$ male, $2=$ female

$F E V_{l}$ forced expiratory volume in $1 \mathrm{~s}, H A D S$ hospital anxiety and depression scale 
in percentage change were found between patients who completed a compact rehabilitation program and patients who had completed the intensive program (Mann-Whitney $U=2,314.5, p=.70$ ).

No significant differences were found between patients who improved their walking distance by at least $10 \%(n=70)$ and those who had less than $10 \%$ increase in distance walked $(n=69)$ with regard to age, weight, height, lung function, symptoms of anxiety and depression, or beliefs about treatment (MANOVA $F(8$, 126) $=0.35, p=.94$; see also Table 4 for univariate comparisons). All variables proved non-significant contributors to the explanation of variance in 6-MW improvement (hierarchical logistic regression analysis; data not shown).

Next, it was investigated whether the relation of treatment beliefs with change in walk distance would depend on the severity of patients' airflow obstruction. This moderation analysis demonstrated there was a significant interaction effect of airway function and patients' concerns about exercise on improvement in walk distance (see Table 5). To explore the direction of the interaction effect, two subgroups were created based on patients' lung function $\left(\mathrm{FEV}_{1}>50 \%(\mathrm{GOLD} \mathrm{I} / \mathrm{II})\right.$ and $\mathrm{FEV}_{1} \leq 50 \%$ (GOLD III/IV)). Patients' concerns were recoded into a low and high concerns group based on a median split. For patients with mild to moderate airway obstruction (GOLD I/II), higher concerns about exercise were negatively related to increase in walk distance (Fig. 1). Whereas $73 \%$ of the patients with no or minor concerns had increased their walk distance with at least $10 \%$, this proportion was only $44 \%$ among those with many concerns $\left(\mathrm{Chi}^{2}=4.43, p=.04\right)$. By contrast, among patients with (very) severe airway obstruction, the proportion of patients who had substantially improved their walk distance was smaller in the group with fewer concerns about exercise than in the group of patients who were more concerned (39\% vs. 52\%, respectively). This difference however was not significant $\left(\mathrm{Chi}^{2}=1.65 \cdot p=.20\right)$.

\section{Discussion}

This study has demonstrated that after correcting for the influence of physical variables, COPD patients' concerns about exercising in a rehabilitation program are related to the outcomes of the baseline 6-MW test and patients' improvement in walk distance after completing a pulmonary rehabilitation program. Results showed that concerns about exercise had a modest but significant negative impact on patients' baseline test results. It was also demonstrated that for patients with mild to moderate airflow obstruction, having many concerns about the negative effects of exercise negatively influenced response to treatment (an improvement of walk distance by $10 \%$ or more [40]). ZuWallack et al. have suggested that patients with better lung function may have a greater potential to train at higher intensity, but that some patients may be "underachievers" [26]. Our data support this hypothesis by showing that for patients with mild to moderate airflow obstruction, the term "underachievers" might represent those individuals with serious concerns about physical exercise.

In patients with severe airflow obstruction, the proportion of patients achieving the MID of $10 \%$ in walk distance was approximately similar for patients with minor concerns and patients with major concerns about the rehabilitation program. Although not reaching significance, it is interesting to note that patients with minor concerns about the exercise program less frequently achieved the MID in walk distance than patients who were more concerned (39\% vs. $52 \%$, respectively), which seems counterintuitive. A possible explanation for this result is that patients with (very) severe COPD who are not concerned about physical exertion at all may also show an inefficient adaptation to the limitations of their disease. Therefore, treatment objectives for patients with severe COPD who have no or little reservations concerning exercising are likely to aim at teaching patients disease management techniques such as energy conservation, pacing, planning, and prioritizing rather than at increasing patients' walk distance [43].
Table 4 Univariate comparison of sociodemographic and clinical characteristics, negative affect, and treatment beliefs between patients with more and patients with less than $10 \%$ increase in walk distance

Values are presented as mean (SD)

$F E V_{1}$ forced expiratory volume in $1 \mathrm{~s}, H A D S$ hospital anxiety and depression scale

\begin{tabular}{lccr}
\hline & $\begin{array}{c}\text { Patients with }<10 \% \text { increase } \\
\text { in 6MWD }(N=67)\end{array}$ & $\begin{array}{l}\text { Patients with } \geq 10 \% \text { increase } \\
\text { in 6MWD }(N=68)\end{array}$ & $p$ \\
\hline Age & $63.8(8.9)$ & $63.6(9.3)$ & .90 \\
Weight & $76.0(16.5)$ & $78.6(18.5)$ & .39 \\
Height & $1.7(0.1)$ & $1.7(0.1)$ & .78 \\
FEV $\%$ pred & $43.8(18.4)$ & $48.2(19.2)$ & .18 \\
HADS anxiety & $7.4(5.2)$ & $6.9(4.7)$ & .55 \\
HADS depression & $7.7(3.9)$ & $7.2(3.9)$ & .46 \\
Treatment necessity & $5.5(1.2)$ & $5.5(1.1)$ & .86 \\
Treatment concerns & $2.9(1.5)$ & $2.8(1.5)$ & .91 \\
\hline
\end{tabular}


Table 5 Predictors of improvement in 6MWD $(N=137)$

$F E V_{1}$ forced expiratory volume in $1 \mathrm{~s}$

Contrary to our hypothesis, we did not find any association of patients' perceived necessity of treatment with the outcomes of the baseline 6MWT or response to treatment. This result may be partly explained by the fact that most patients had high necessity scores $(70 \%$ of the patients had a necessity score of 5 or higher on a seven-point scale). This may result in decreased power of the statistical tests. Additionally, the content of the concern items appears to be more closely related to the exercise component within the rehabilitation program than the necessity items and may therefore exert a stronger influence on patients' exercise behavior.

Previous studies have obtained inconsistent results with regard to the relationship between indices of negative affect and exercise tolerance and response to treatment in patients with COPD [2-5]. One explanation for the lack of association in the studies by Borak et al. [2] and Trappenburg et al. [3] might have been the rather small patient samples in those studies (49 and 65 patients, respectively). However, also in the present study with a larger patient sample, negative affect and baseline exercise tolerance or response to exercise training were unrelated. Our findings and those of Borak and Trappenburg suggest that global indices of anxiety and depression, such as the HADS, are less well suited to capture the specific affective processes involved in COPD patients' exercise behavior. In a preliminary additional examination of our data, it was found that patients with more concerns about exercise were also more emotionally affected by their disease (as measured with a disease-specific measure, the Illness

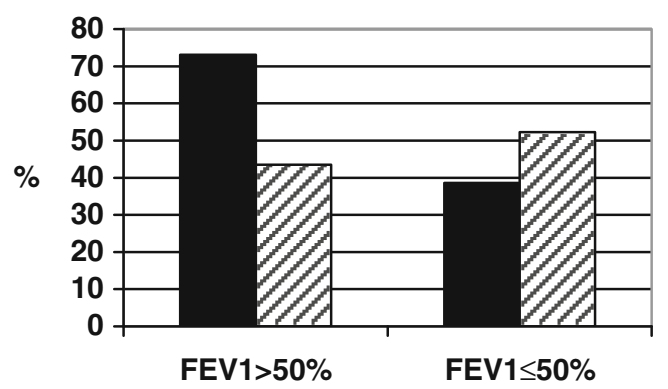

Low concerns 圈 High concerns

Fig. 1 Percentage of patients with $\geq 10 \%$ increase in 6-min walk distance
Perception Questionnaire-Revised [44]), suggesting that affective processes are indeed involved. Therefore, future investigations into the role of affective processes involved in exercise intolerance of patients with COPD should include measures that assess fears that are specifically related to exercise (e.g., using an adapted version of the Tampa scale for kinesiophobia [45]) and affective reactions to physical sensations (e.g., Anxiety Sensitivity Index [46]), which are likely to occur during exertion.

Some limitations to this study must be acknowledged. Firstly, apart from forced expiratory volume, no other parameters of lung function were included in the analyses. Forced expiratory volume was included since it is currently the most important parameter of disease severity in COPD. Furthermore, it has been demonstrated to be related to walk test results [2, 27, 32, 33], but appeared unrelated to the improvement in walk distance after an exercise program [26, 39, 47, 48]. Future studies with an extended set of physiological parameters (e.g., inspiratory capacity/total lung capacity, muscle strength, and comorbidities) are required to further investigate how cognitions and emotions influence patients' exercise tolerance and response to treatment after correction for these physical parameters.

A second limitation pertains to the internal consistency of the necessity and concerns subscale. It is possible that both scales refer to multiple underlying constructs. For instance, the necessity scale includes items about goal clarity ("I have a clear picture of what I want to achieve by attending pulmonary rehabilitation") and outcome expectations ("My physical condition will improve considerably if I attend the rehabilitation program for 12 weeks"). In a similar manner, the concerns scale includes items on patients' expectations about the outcomes of exercising ("Some aspects of the rehabilitation program may be harmful to me") and their beliefs about their confidence (self-efficacy) to comply with the treatment protocol ("I may not be physically fit enough to participate in the rehabilitation program"). Both types of beliefs (outcome expectancies and self-efficacy beliefs) are relevant for patients' exercise behavior in a rehabilitation setting [49-51]. Therefore, further studies should employ separate measures for outcome expectancies and self-efficacy expectations with regard to 
exercise to explore which type of beliefs are more closely related to patients' behavior.

A further limitation to this study is that we have not investigated whether patients' treatment beliefs change during rehabilitation. These changes in cognitions may be more strongly related to outcomes of rehabilitation than patients' pre-treatment beliefs. We suggest future studies to examine possible changes in patients' beliefs to further our understanding of the relation between patients' cognitions and treatment outcomes.

Notwithstanding these limitations, we feel that our study has some implications for clinical practice. The present study shows that patients' concerns about exercise are negatively related to walk test results and response to treatment for patients with mild airflow impairment. Currently, COPD patients' concerns about treatment tend to be underrepresented in the communication between patients and healthcare providers [52]. Therefore, we suggest that patients' treatment beliefs are discussed explicitly, preferably before the start of treatment. Uncovering patients' concerns about treatment may help physicians understand abnormal exercise test results that cannot be explained by physical parameters alone. Furthermore, correcting unrealistic fears and tailoring the program to the demands of the individual patient might not only improve treatment uptake and adherence but also can have a beneficial effect on treatment outcomes, in particular for patients with mild to moderate airflow obstruction.

Acknowledgements The authors would like to thank the participating patients for their time. The present study was supported by a grant from the Netherlands Asthma Fund (protocol: 3.4.03.80).

Open Access This article is distributed under the terms of the Creative Commons Attribution Noncommercial License which permits any noncommercial use, distribution, and reproduction in any medium, provided the original author(s) and source are credited.

\section{Appendix 1}

Items covering beliefs about exercise

\section{Necessity}

1. I have a clear picture of how pulmonary rehabilitation will improve the condition of my lungs.

2. I have a clear picture of what I want to achieve by attending pulmonary rehabilitation.

3. My physical condition will improve considerably if I attend the rehabilitation program for 12 weeks.

4. Some aspects of the rehabilitation program are unnecessary for me. ${ }^{1}$

\footnotetext{
${ }^{1}$ This item was reverse scored.
}

5. I hope that attending pulmonary rehabilitation may help me resume my activities more quickly.

\section{Concerns}

1. Some aspects of the rehabilitation program may be harmful to me.

2. I may not be physically fit enough to participate in the rehabilitation program.

3. In the days in between the rehabilitation sessions, I am probably very tired from exercising.

\section{References}

1. Nici L, Donner C, Wouters E, Zuwallack R, Ambrosino N, Bourbeau J, et al. American Thoracic Society/European Respiratory Society statement on pulmonary rehabilitation. Am J Respir Crit Care Med. 2006;173:1390-413.

2. Borak J, Chodosowska E, Matuszewski A, Zielinski J. Emotional status does not alter exercise tolerance in patients with chronic obstructive pulmonary disease. Eur Respir J. 1998;12:370-3.

3. Trappenburg JC, Troosters T, Spruit MA, Vandebrouck N, Decramer M, Gosselink R. Psychosocial conditions do not affect short-term outcome of multidisciplinary rehabilitation in chronic obstructive pulmonary disease. Arch Phys Med Rehabil. 2005;86:1788-92.

4. Cully JA, Graham DP, Stanley MA, Ferguson CJ, Sharafkhaneh A, Souchek J, et al. Quality of life in patients with chronic obstructive pulmonary disease and comorbid anxiety or depression. Psychosomatics. 2006;47:312-9.

5. Giardino N, Curtis J, Andrei AC, Fan V, Benditt J, Lyubkin M, et al. Anxiety is associated with diminished exercise performance and quality of life in severe emphysema: a cross-sectional study. Respir Res. 2010;11:29. http://respiratory-research.com/content/11/1/29.

6. Fishbein M, Ajzen I. Belief, attitude, intention, and behavior: an introduction to theory and research. Reading, MA: AddisonWesley; 1975.

7. Janz NK, Becker MH. The health belief model: a decade later. Health Educ Q. 1984;11:1-47.

8. Horne R. Treatment perceptions and self-regulation. In: Cameron $\mathrm{LD}$, Leventhal H, editors. The self-regulation of health and illness behaviour. New York, NY: Routledge; 2003. p. 138-53.

9. Leventhal H, Meyer D, Nerenz D. The common sense representation of illness danger. In: Rachman S, editor. Contributions to medical psychology, vol. 2. New York, NY: Pergamon; 1980. p. 7-30.

10. Leventhal H, Nerenz D, Steele DJ. Illness representations and coping with health threats. In: Baum A, Taylor SE, Singer JE, editors. Handbook of psychology and health: social psychological aspects of health, vol. 4. Hillsdale, NJ: Lawrence Erlbaum Associates; 1984. p. 219-52.

11. Horne R. Patients' beliefs about treatment: the hidden determinant of treatment outcome? J Psychosom Res. 1999;47:491-5.

12. Bucks RS, Hawkins K, Skinner TC, Horn S, Seddon P, Horne R. Adherence to treatment in adolescents with cystic fibrosis: the role of illness perceptions and treatment beliefs. J Pediatr Psychol. 2009;34:893-902.

13. Cooper AF, Weinman J, Hankins M, Jackson G, Horne R. Assessing patients' beliefs about cardiac rehabilitation as a basis for predicting attendance after acute myocardial infarction. Heart. 2007;93:53-8. 
14. Fischer MJ, Scharloo M, Abbink JJ, Thijs-Van Nies A, Rudolphus A, Snoei L, et al. Participation and drop-out in pulmonary rehabilitation: a qualitative analysis of the patient's perspective. Clin Rehabil. 2007;21:212-21.

15. Haughney J, Price D, Kaplan A, Chrystyn H, Horne R, May N, et al. Achieving asthma control in practice: understanding the reasons for poor control. Respir Med. 2008;102:1681-93.

16. Horne R, Parham R, Driscoll R, Robinson A. Patients' attitudes to medicines and adherence to maintenance treatment in inflammatory bowel disease. Inflamm Bowel Dis. 2009;15:837-44.

17. Lane DA, Langman CM, Lip GYH, Nouwen A. Illness perceptions, affective response, and health-related quality of life in patients with atrial fibrillation. J Psychosom Res. 2009;66:20310 .

18. Menckeberg TT, Bouvy ML, Bracke M, Kaptein AA, Leufkens HG, Raaijmakers JAM, et al. Beliefs about medicines predict refill adherence to inhaled corticosteroids. J Psychosom Res. 2008;64:4754.

19. Al-Obaidi S, Beattie P, Al-Zoabi B, Al-Wekeel S. The relationship of anticipated pain and fear avoidance beliefs to outcome in patients with chronic low back pain who are not receiving workers' compensation. Spine. 2005;30:1051-7.

20. George SZ, Fritz JM, Childs JD. Investigation of elevated fearavoidance beliefs for patients with low back pain: a secondary analysis involving patients enrolled in physical therapy clinical trials. J Orthop Sports Phys Ther. 2008;38:50-8.

21. Morlock RJ, Lafata JE, Nerenz D, Schiller M, Rosenblum M. Expectations, outcomes, and medical costs in patients with low back pain referred to physical therapy. Dis Man. 2002;5:185-8.

22. Ries AL, Bauldoff GS, Carlin BW, Casaburi R, Emery CF, Mahler DA, et al. Pulmonary rehabilitation: joint ACCP/AACVPR evidence-based clinical practice guidelines. Chest. 2007;131 (5 suppl):4S-42S.

23. Troosters T, Casaburi R, Gosselink R, Decramer M. Pulmonary rehabilitation in chronic obstructive pulmonary disease. Am J Respir Crit Care Med. 2005;172:19-38.

24. Ajzen I, Fishbein M. Attitude-behavior relations: a theoretical analysis and review of empirical research. Psychol Bull. 1977;84:888-918.

25. Conner M, Sparks P. The theory of planned behaviour and health behaviours. In: Conner M, Norman P, editors. Predicting health behaviour. Buckingham: Open University Press; 1996. p. 121-62.

26. ZuWallack RL, Patel K, Reardon JZ, Clark III BA, Normandin EA. Predictors of improvement in the 12-minute walking distance following a six-week outpatient pulmonary rehabilitation program. Chest. 1991;99:805-8.

27. Cote CG, Pinto-Plata V, Kasprzyk K, Dordelly LJ, Celli BR. The 6-min walk distance, peak oxygen uptake, and mortality in COPD. Chest. 2007;132:1778-85.

28. Palange P, Ward SA, Carlsen KH, Casaburi R, Gallagher CG, Gosselink R, et al. Recommendations on the use of exercise testing in clinical practice. Eur Respir J. 2007;29:185-209.

29. Enright PL, McBurnie MA, Bittner V, Tracy RP, McNamara R, Arnold A, et al. The 6-minute walk test. Chest. 2003;123:387-98.

30. Troosters T, Gosselink R, Decramer M. Six minute walking distance in healthy elderly subjects. Eur Respir J. 1999;14:270-4.

31. Camarri B, Eastwood PR, Cecins NM, Thompson PJ, Jenkins S. Six minute walk distance in healthy subjects aged $55-75$ years. Respir Med. 2006;100:658-65.

32. Huijsmans RJ, de Haan A, ten Hacken NNHT, Straver RVM, van't Hul AJ. The clinical utility of the GOLD classification of COPD disease severity in pulmonary rehabilitation. Respir Med. 2008;102:162-71.

33. Wijkstra PJ, ten Vergert EM, van der Mark TW, Postma DS, van Altena R, Kraan J, et al. Relation of lung function, maximal inspiratory pressure, dyspnoea, and quality of life with exercise capacity in patients with chronic obstructive pulmonary disease. Thorax. 1994;49:468-72.

34. Rabe KF, Hurd S, Anzueto A, Barnes PJ, Buist SA, Calverley P, et al. Global strategy for the diagnosis, management, and prevention of chronic obstructive pulmonary disease: GOLD executive summary. Am J Respir Crit Care Med. 2007;176:532-55.

35. Zigmond AS, Snaith RP. The hospital anxiety and depression scale. Acta Psychiatr Scand. 1983;67:361-70.

36. Global Initiative for Chronic Obstructive Lung Disease (GOLD). Global strategy for the diagnosis, management, and prevention of chronic obstructive pulmonary disease (updated 2008). 2008. Available from: www.goldcopd.com

37. Rabe KF, Beghe B, Luppi F, Fabbri LM. Update in chronic obstructive pulmonary disease 2006. Am J Respir Crit Care Med. 2007; 175:1222-32.

38. Borg GAV. Psychophysical bases of physical exertion. Med Sci Sports Exerc. 1982;14:377-81.

39. Troosters T, Gosselink R, Decramer M. Exercise training in COPD: how to distinguish responders from nonresponders. $\mathrm{J}$ Cardiopulm Rehabil. 2001;21:10-7.

40. Puhan MA, Mador MJ, Held U, Goldstein R, Guyatt GH, Schunemann HJ. Interpretation of treatment changes in 6-minute walk distance in patients with COPD. Eur Respir J. 2008;32:63743.

41. Frazier PA, Tix AP, Barron KE. Testing moderator and mediator effects in counseling psychology research. J Counsel Psychol. 2004;51:115-34.

42. Fischer MJ, Scharloo M, Abbink JJ, van't Hul AJ, van Ranst D, Rudolphus A, et al. Drop-out and attendance in pulmonary rehabilitation: the role of clinical and psychosocial variables. Respir Med. 2009;103:1564-71.

43. Velloso M, Jardim JR. Study of energy expenditure during activities of daily living using and not using body position recommended by energy conservation techniques in patients with COPD. Chest. 2006;130:126-32.

44. Moss-Morris R, Weinman J, Petrie KJ, Horne R, Cameron LD, Buick D. The revised Illness Perception Questionnaire (IPQ-R). Psychol Health. 2002;17:1-16.

45. Roelofs J, Sluiter JK, Frings-Dresen MHW, Goossens M, Thibault P, Boersma K, et al. Fear of movement and (re)injury in chronic musculoskeletal pain: evidence for an invariant twofactor model of the Tampa scale for kinesiophobia across pain diagnoses and Dutch, Swedish, and Canadian samples. Pain. 2007;13:181-90.

46. Blais MA, Otto MW, Zucker BG, McNally RJ, Schmidt NB, Fava $\mathrm{M}$, et al. The anxiety sensitivity index: item analysis and suggestions for refinement. J Pers Assess. 2001;77:272-94.

47. Ferreira GM, Feuerman M, Spiegler PM. Results of an 8-week, outpatient pulmonary rehabilitation program on patients with and without chronic obstructive pulmonary disease. J Cardiopulm Rehabil. 2006;26:54-60.

48. Garrod R, Marshall J, Barley E, Jones PW. Predictors of success and failure in pulmonary rehabilitation. Eur Respir J. 2006;27:788-94.

49. Atkins CJ, Kaplan RM, Timms RM, Reinsch S, Lofback K. Behavioral exercise programs in the management of chronic obstructive pulmonary disease. J Consult Clin Psychol. 1984;52:591-603.

50. Blanchard CM, Courneya KS, Rodgers WM, Fraser SN, Murray TC, Daub B, et al. Is the theory of planned behavior a useful framework for understanding exercise adherence during phase II cardiac rehabilitation? J Cardiopulm Rehabil. 2003;23:29-39.

51. Scherer YK, Schmieder LE. The effect of a pulmonary rehabilitation program on self-efficacy, perception of dyspnea, and physical endurance. Heart Lung. 1997;26:15-22.

52. Bourbeau J, Bartlett SJ. Patient adherence in COPD. Thorax. 2008;63:831-8 